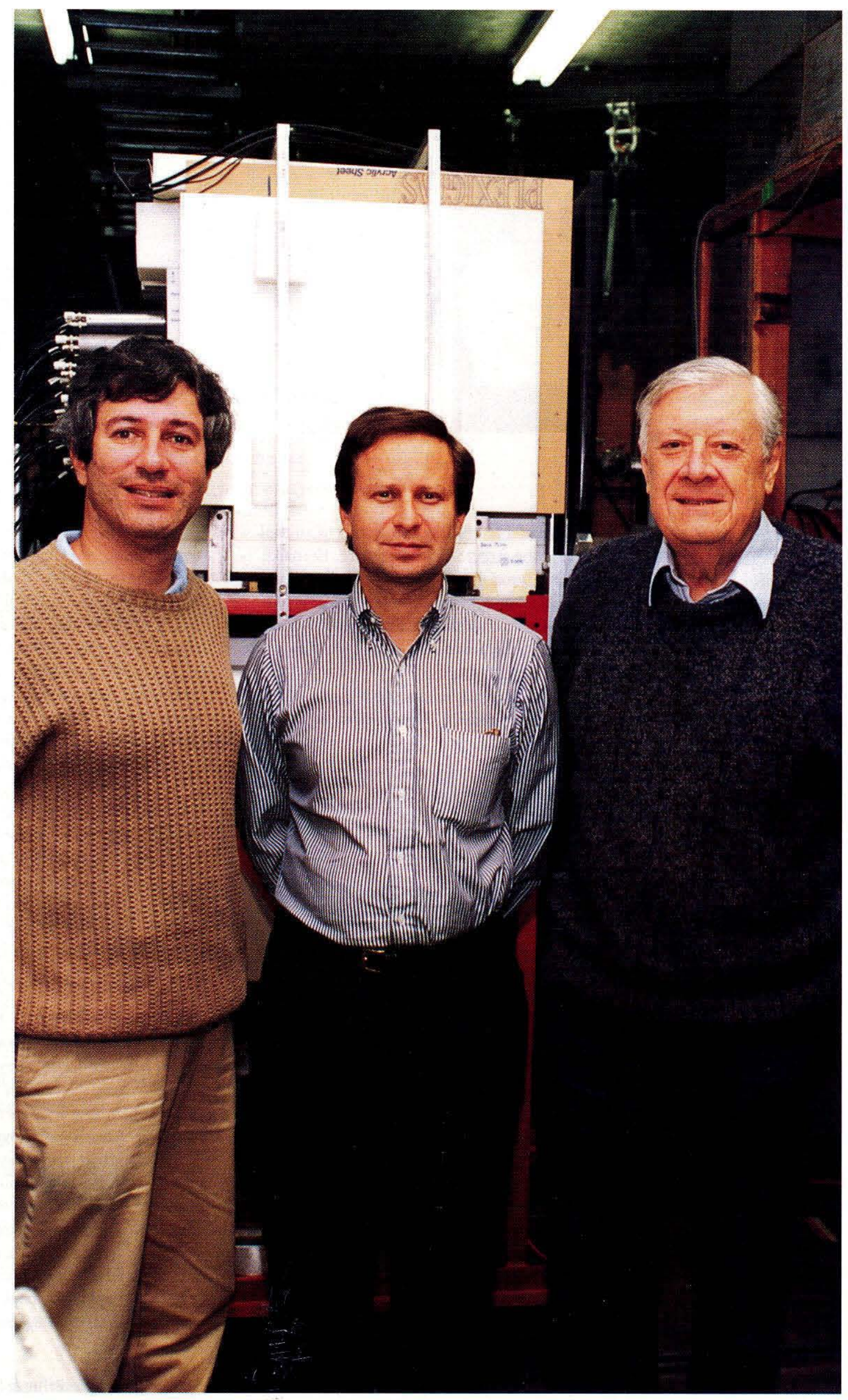




\section{Whatever Happened to Cold Fusion?}

by David L. Goodstein

On December 6-9, 1993, the Fourth International Conference on Cold Fusion took place on the island of Maui, in Hawaii. It had all the trappings of a normal scientific meeting. Two hundred and fifty scientists took part, mostly from the United States and Japan (hence the site in Hawaii), but also a sprinkling from Italy, France, Russia, China, and other countries. More than 150 scientific papers were presented on subjects such as calorimetry, nuclear theory, materials, and so on. The founders of the field, Stanley Pons and Martin Fleischmann, were in attendance and were treated with the deference due their celebrity status. Pons and Fleischmann carry out their research today in a laboratory built for them in Nice, on the French Riviera, by TECHNOVA, a subsidiary of Toyota. At the meeting it was announced that the Japanese trade ministry, MITI, has committed $\$ 30$ million over a period of four years to support research on what was delicately called "new hydrogen energy," including cold fusion.

Contrary to appearances, however, this was no normal scientific conference. Cold fusion is a pariah field, cast out by the scientific establishment. Between cold fusion and respectable science there is virtually no communication at all. Cold fusion papers are almost never published in refereed scientific journals, with the result that those works don't receive the normal critical scrutiny that science requires. On the other hand, because the cold-fusioners see themselves as a community under siege, there is little internal criticism. Experiments and theories tend to be accepted at face value, for fear of providing even

According to
everything we
know about the
bebavior of mat-
ter and nuclei,
cold fusion is
impossible.

more fuel for external critics, if anyone outside the group was bothering to listen. In these circumstances, crackpots flourish, making matters worse for those who believe that there is serious science going on here.

The origins of cold fusion have been loudly and widely documented in the press and popular literature. Pons and Fleischmann, fearing they were about to be scooped by a competitor named Steven Jones from nearby Brigham Young University, and with the encouragement of their own administration, held a press conference on March 23,1989 , at the University of Utah, to announce what seemed to be the scientific discovery of the century. Nuclear fusion, producing usable amounts of heat, could be induced to take place on a tabletop by electrolyzing heavy water, using electrodes made of palladium and platinum, two precious metals. If so, the world's energy problems were at an end, to say nothing of the fiscal difficulties of the University of Utah. What followed was a kind of feeding frenzy, science by press conference and e-mail, confirmations and disconfirmations, claims and retractions, ugly charges and obfuscation, science gone berserk. For all practical purposes, it ended a mere five weeks after it began, on May 1, 1989, at a dramatic session of the American Physical Society, in Baltimore. Although there were numerous presentations at this session, only two really counted. Steven Koonin and Nathan Lewis, speaking for himself and Charles Barnes, all three from Caltech, executed between them a perfect slam-dunk that cast cold fusion right out of the arena of mainstream science. 


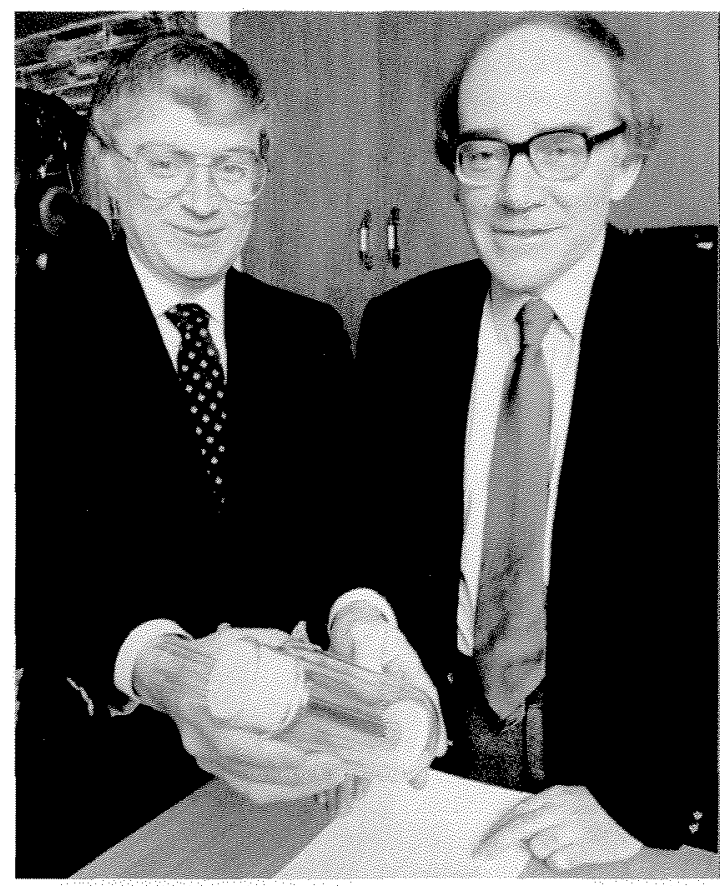

Before I go any further in telling this tale, I think l'd better come clean about my own prejudices. (Those of us concerned about the issue of conflicts of interest in academic life refer to this as "disclosure." It's supposed to help protect us from sin.) The Caltech protagonists, Steve Koonin, Nate Lewis, and Charlie Barnes,

The chemists had beaten the physicists, little science had beaten big science, cleverness had prevailed over brute force, two bumble professors from Utah had won out over the aristocrats of bicoastal, non-Mormon America. are not only my faculty colleagues, I count them all among my personal friends of many years. On the other hand, there is a player on the other side of this game who is also one of my oldest personal friends, and who is, besides, my longtime scientific collaborator. His story is one that, because it took place outside the United States, was largely off the radar screen of our journalists and popular authors. Nevertheless, the story is worth telling. It shows at the very least that the frenzy that began in Utah was not an isolated or unique phenomenon.

My friend, Professor Francesco (Franco) Scaramuzzi, is the head of a small low-temperature physics research group at a national laboratory in Frascati (a suburb of Rome), Italy, run by an agency called ENEA, roughly analogous to our Department of Energy. It is possible within this agency for a scientist like my friend Franco to be promoted to the rank of Dirigente (executive). The promotion would not change in any substantial way his assignment or responsibilities, but it would carry with it very substantial financial rewards and much prestige. Although Franco was certainly one of the laboratory's more distinguished scientists long before cold fusion appeared on the scene, he had not been awarded this promotion by 1989 , when he was 61 years
At a press conference on March 23, 1989 at the University of Utah, R. Stanley Pons (left) and Martin Fleischmann announced that they had created nuclear fusion at room temperature in the flask they display here. When other scientists got through debunking what was supposed to be the discovery of the century, cold fusion looked effectively dead.

old. The reason is that, in the corrupt Italian system that has collapsed only recently, these promotions were based on political affiliation more than scientific accomplishment. For every two Christian Democrats promoted, there would also be a new Socialist, a Communist, and someone from one of the smaller parties among the ranks of the Dirigenti. Franco had not been promoted because he refused to join a political party in order to advance his professional career as a scientist. Franco is, in other words, a man of unflinching integrity.

On the morning of April 18, 1989, Franco called to warn me that I would find his picture in the New York Times the next day (I did). He had just come out of a press conference announcing the discovery of a new kind of cold fusion.

Like scientists everywhere, he had heard of the Utah announcement and decided to give it a try. He reasoned that electrolysis wasn't really necessary. It served only to get deuterium (the hydrogen isotope in heavy water) to insert itself into the atomic lattice of the palladium electrode. He also thought it necessary that the system not be in thermodynamic equilibrium. He and his handful of young scientists and technicians arranged to put some titanium shavings in a cell pressurized with deuterium gas (titanium is both cheaper and easier to get hold of than palladium, and, like palladium, it is a metal that absorbs large quantities of hydrogen or deuterium into its atomic crystal lattice). Then they used some liquid nitrogen (a refrigerant readily available in any low-temperature physics laboratory) to run the temperature of the cell up and down, thus 


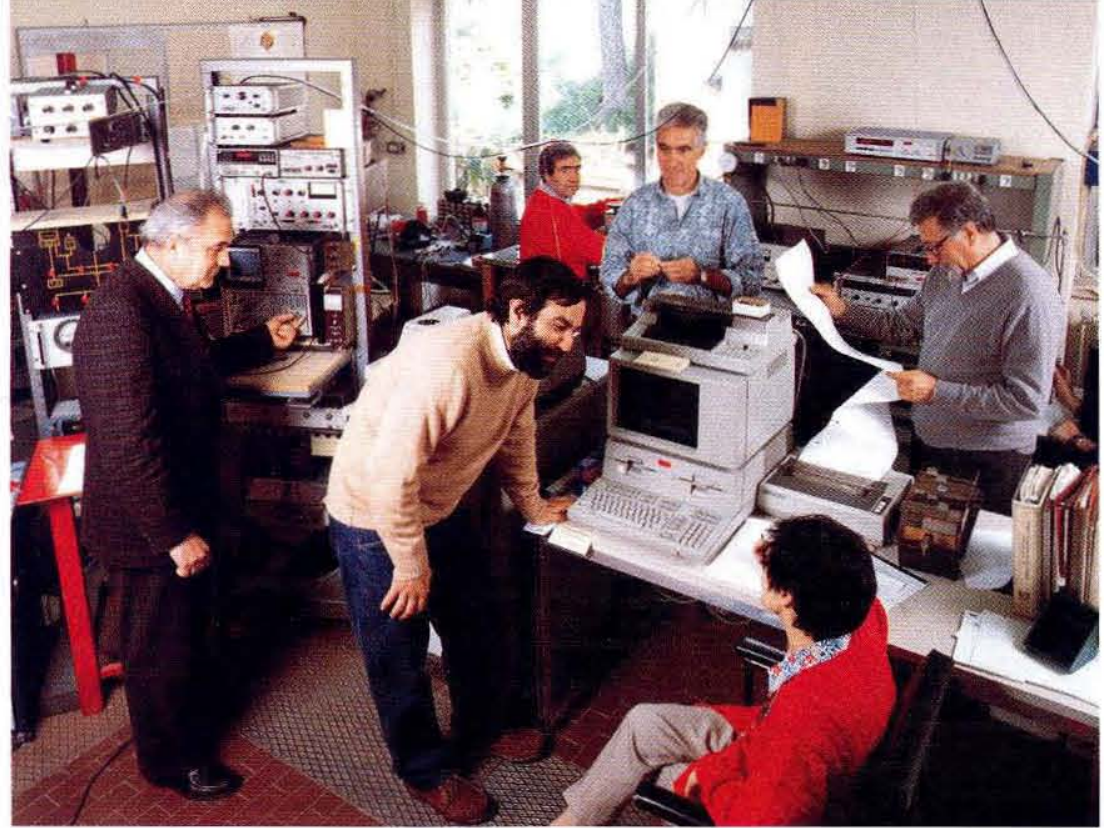

Meanwhile, back in

Italy, physicists at the

ENEA lab in Franscati

continued experi-

ments on Fusione

Fredda. Here, two

days after the April

press conference

announcing their

observations created

a national furor,

members of the lab

stay busy. Prof.

Franco Scaramuzzi

checks data at right;

from left (foreground)

are Prof. Marcello

Martone, Dr. Salvatore

Podda, Dr. Antonella

De Ninno; (in back)

Giuseppe Lollobattis-

ta, and Lorenzo

Martinis. creating thermodynamic disequilibrium. The crude apparatus was not suitable for the difficult measurement needed to tell whether any heat was being generated, but fusion should produce neutrons (that is what Steven Jones had claimed to detect at BYU). They got a colleague at the Frascati lab to set up a neutron detector near their apparatus. In the course of their experiments, they often detected nothing at all, but on a couple of occasions, their detector indicated very substantial bursts of neutrons.

When the second positive result was discovered on April 17, Franco decided he had to inform the head of his laboratory. In no time at all, he found himself in downtown Rome, talking about it to the head of the entire national agency.

The agency ENEA had been without funding for four months. The necessary legislation was stalled in Parliament. ENEA was borrowing money from banks to meet its payroll. All purchases were frozen. Research was paralyzed. To the politically astute agency head, Scaramuzzi's discovery was an opportunity not to be missed. Franco agreed to a press conference, but only if he could give a full technical seminar to his scientific peers first. The seminar, hastily organized for that same day, was crammed to the rafters with scientists from every laboratory in the Rome area, and was even covered by the evening television news programs. At the press conference the next morning, Franco, stunned to find himself flanked by two ministers of state, did his best to behave with the utmost scientific objectivity and reserve, but it made not the slightest bit of difference. The story made headlines all over
Italy. Within days, Parliament had approved financing for ENEA and Franco had been promoted to Dirigente. The agency was solvent once more, and Franco's personal salary had increased overnight from one that would be meager for an American postdoc to one that would be generous for an American full professor.

He had also become the Italian Prometheus, stealing fire from the sun. My very reserved, correct, self-effacing friend was a media celebrity, suddenly the most famous scientist in Italy. When I came to visit just a few months later, in the summer of 1989, he handed me two books, each two or three inches thick, of photocopies of his press notices in Italy and abroad. Although it happened far offstage for most Americans, what happened in Italy had mirrored in many important ways the feeding frenzy in the United States.

For one thing, pecuniary motives had driven science out of the laboratory into the blinding glare of publicity. For another, the story instantly captured the public fancy. Not only were the gallant scientists about to rescue us from the grip of the greedy oil barons (the whole affair took place just shortly after the Exxon Valdez incident), the story was spiced with lots of delicious ironies. In America, mere chemists, spending money out of their own pockets, seemed to have succeeded where arrogant physicists spending hundreds of millions of dollars of public funds had conspicuously failed: they had produced controlled nuclear fusion. The chemists had beaten the physicists, little science had beaten big science, cleverness had prevailed over brute force, two humble professors from Utah had won out over the aristocrats of bicoastal, non-Mormon America. (True, the two Utah professors, Pons and Jones, were bitter rivals. Jones, the only Mormon of the bunch, was a physicist, not a chemist, and Pons's partner Fleischmann was not only an Englishman, but an Fellow of the Royal Society. These were mere footnotes, however.) Much the same was true in Italy. The dire straits of ENEA drove the story out of the lab and into the headlines. Not only had cold fusion been reproduced in Italy, the Italian version was of an entirely new kind: Fusione Fredda, or Cold Fusion Italian Style, was "dry fusion," that is, without electrolysis. True, Scaramuzzi was also a physicist, not a chemist, but he did small, clever, low-budget science in the Frascati lab, which is better known for its hot fusion and synchrotron-type big science. Suddenly, Italy had more to give the world than sunshine and pasta. An Italian scientific hero strode the world stage (or so it seemed from inside Italy). 


\section{The failure of \\ cold fusion was \\ due, above all, to \\ the fact that it \\ was an experi- \\ ment whose result \\ was contrary to \\ prevailing theory.}

The cold fusion story seemed to stand science on its head, not only because it was played out in the popular press without the ritual of peerreview, but also because both sides of the debate violated what are generally supposed to be the central canons of scientific logic. Science in the 20th century has been much influenced by the ideas of the Austrian philosopher Karl Popper. Popper argued that a scientific idea can never be proven true, because no matter how many observations seem to agree with it, it may still be wrong. On the other hand, a single contrary experiment can prove a theory forever false. Therefore, science advances only by demonstrating that theories are false, so that they must be replaced by better ones. The proponents of cold fusion took exactly the opposite view: many experiments, including their own, failed to yield the expected results. These were irrelevant, they argued, incompetently done, or lacking some crucial (perhaps unknown) ingredient needed to make the thing work. Instead, all positive results, the appearance of excess heat, or a few neutrons, proved the phenomenon was real. This anti-Popperian flavor of cold fusion played no small role in its downfall, since seasoned experimentalists like Lewis and Barnes refused to believe what they couldn't reproduce in their own laboratories. To them, negative results still mattered.

On the other hand, the anti-cold-fusion crowd was equally guilty, if you believe another of the solemn canons: it is said in all the high school textbooks that science must be firmly rooted in experiment or observation, unladen with theoret- ical preconceptions. On the contrary, however, the failure of cold fusion was due, above all, to the fact that it was an experiment whose result was contrary to prevailing theory.

All parties agreed that, if cold fusion occurred in the experiments of Pons and Fleischmann, Jones, Scaramuzzi, and many others, the primary event would have to have been the fusion of the two deuterium nuclei: deuterium nuclei repel one another because of the electric force between them, but if they get close enough together they fuse anyway because of what is called the "strong" (nuclear) force. The laws of quantum mechanics allow deuterium nuclei to fuse by accident every so often even if they are not initially close together, but the probability of that happening is very small. Suppose, for example, they are as far apart as the two deuterium nuclei normally are in a deuterium molecule. Then the probability of fusion is much too small to have produced the alleged effects claimed by the cold-fusioners. There are two ways to look at just how small the probability is. At the internuclear spacing in the deuterium molecule, the probability is too small by 40 or 50 orders of magnitude. Physicists love to throw around phrases like that one. An order of magnitude means a factor of 10 . Too small by 40 or 50 orders of magnitude really means too small beyond discussion, beyond imagination, almost beyond meaning. On the other hand, that probability is insanely sensitive to how far apart the nuclei are to begin with. To increase the probability by the requisite 40 or 50 orders of magnitude requires getting the nuclei closer together by just one order of magnitude. It is extremely difficult to imagine how-given the well-known forces involved - they can be gotten closer together by a factor of 10 in an experiment on a tabletop. In fact, the whole purpose of the hundreds of millions of dollars spent on hot fusion is to produce exactly that result. Nevertheless, once we have been anesthetized by talking about 40 or 50 orders of magnitude, the idea that a one order of magnitude gap might somehow be overcome is not so hard to swallow.

Still the theoretical difficulties of cold fusion don't end with getting the nuclei somehow to fuse. When two deuterium nuclei fuse, they momentarily form the nucleus of the common isotope of helium, called helium- 4 . When that happens, however, there is so much excess energy in the reaction that the helium- 4 almost always breaks up immediately into two smaller pieces. About half of the time, a neutron pops out, leaving a helium- 3 nucleus. The other half of the time, a proton comes off, leaving a hydrogen-3, also known as tritium, nucleus. It also happens 
The debate continued. Here at a meeting of the Electrochemical Society on May 8, 1989 in Los Angeles, Fleishmann responds heatedly to a statement by Caltech electrochemist Nate Lewis (out of picture). Pons, at right, might well be wishing he were elsewhere.

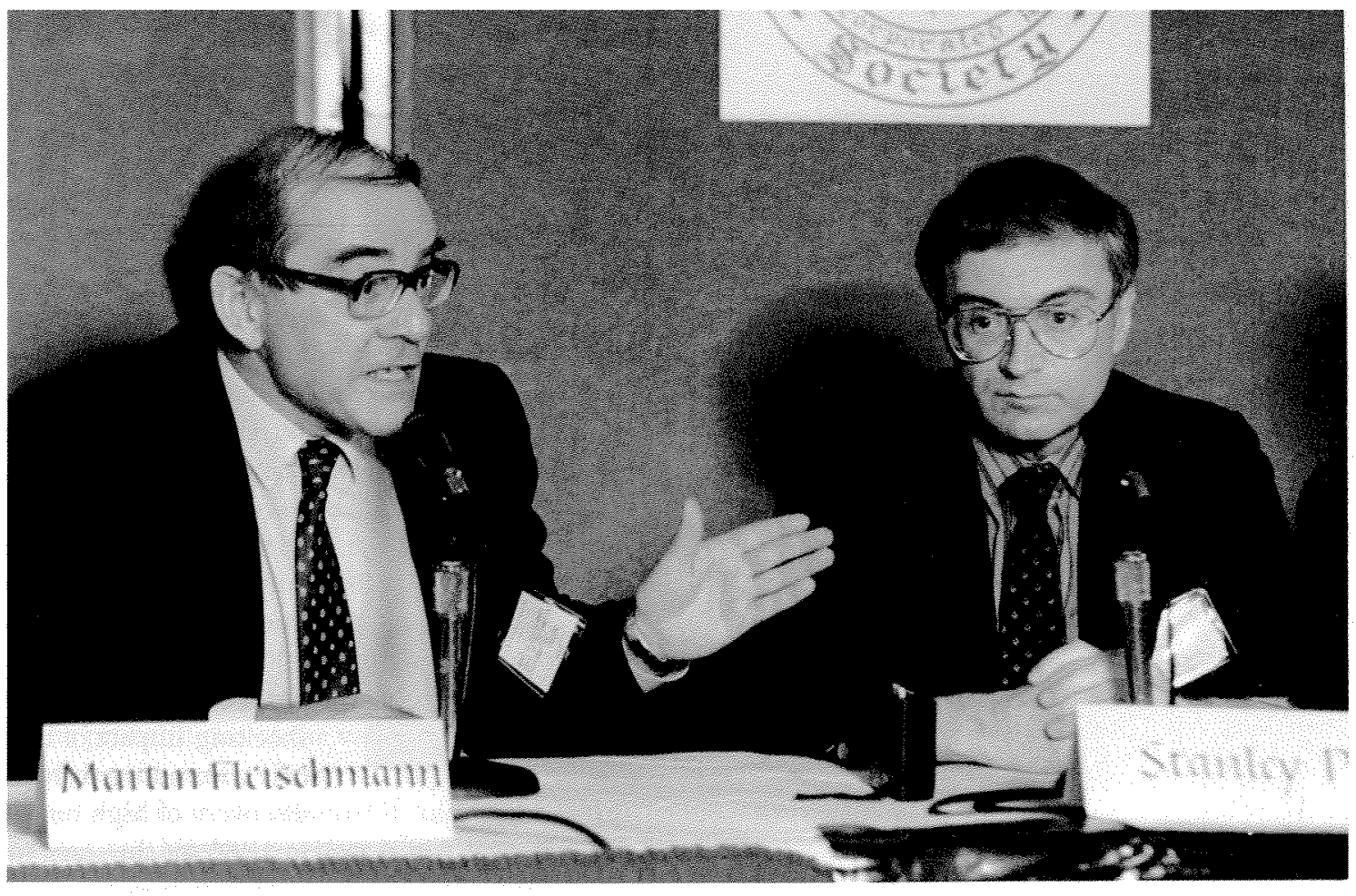

that, one time in a million, the helium-4 doesn't break up at all. Instead, an intact helium-4 nucleus goes zooming off, while emitting a powerful gamma-ray photon. In all cases, the two pieces go off in opposite directions with lots of energy.

What you expect, then, is that about half the fusions will produce energetic neutrons, and the other half will leave behind tritium as evidence they occurred. In fact, as we have already seen, neutrons were detected by Jones, Scaramuzzi, and others, and offered as evidence for cold fusion, but there were always far too few of them to account for the amount of heat being claimed by Pons and Fleischmann (the heat would presumably be the end-product of the energy carried away by the nuclear fragments of the various reactions that could take place). In fact, on the evening of the original Pons and Fleischmann press conference, I ran into one of my buddies at Caltech, a battlescarred veteran of experimental nuclear physics. "What do you think?" I asked (there was no need to be more specific). "It's bullshit," he said, slipping immediately into technical jargon. "If it were true, they'd both be dead." What he meant was that if enough fusions had taken place to produce the amount of heat claimed by Pons and Fleischmann, the flux of neutrons that resulted would have long since been enough to send them both to the happy hunting grounds.

To believe that Pons and Fleischmann, Jones and Scaramuzzi, and many others who claimed to observe either heat or neutrons or tritium were all observing the same phenomenon, one must believe that, when fusion occurs inside a piece of metal, such as palladium or titanium, the outcome is radically different from what is known to happen when fusion occurs in the sun, or in a hot fusion plasma, or an atomic bomb, or a nuclear accelerator. In other words, it is different from conventional nuclear physics. Let's call the three possible outcomes of fusion $a, b$, and $c$. We'll call $a$ the one that emits neutrons, $b$ the one that leaves tritium behind, and $c$ the one where the helium-4 stays intact. In conventional nuclear physics, fusion results about half the time in $a$, half the time in $b$, and one millionth of the time in $c$. To account for the observations reported, with some consistency, by various researchers in cold fusion, fusion inside a metal would nearly always result in reaction $c$ (without, however, emitting a gamma ray). One in every hundredthousand or so reactions would result in $b$, and the probability of a reaction $a$ would be smaller by yet another factor of a hundred thousand. These are the conditions needed to explain why cold fusion cells can generate power at the rate of watts, for periods of days or months, while, far short of killing Pons and Fleischmann, still yielding barely detectable traces of neutrons, and only tiny amounts of tritium.

Is it plausible that the nuclear reaction might be altered radically when it takes place among the atoms in a metal, rather than in a rarefied atmosphere? The answer, quite simply, is no. For one thing, the atomic nucleus is so small compared to the distances between atoms in a metal that for all practical purposes, the nucleus is always in a near vacuum. For another thing, events occur so quickly in the nuclear fusion 


\section{What does Italy's most famous scientist do in the privacy of his own home? Scaramuzzi cooks pasta.}

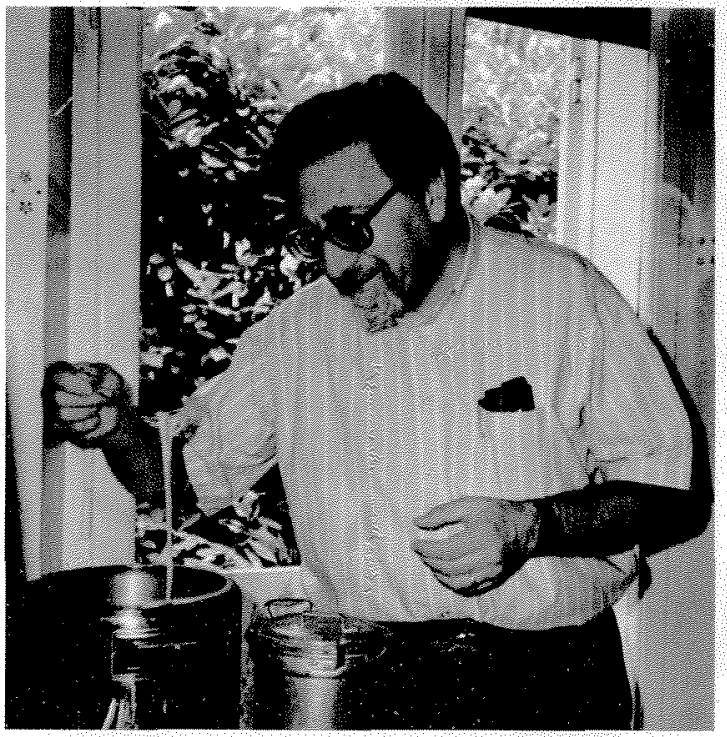

In spite of all

that, scientists are

aware that they

must be prepared,

from time to time,

to be surprised by

a phenomenon they

previously thought

to be impossible. reaction that the metal is simply unable to respond. If you like orders of magnitude, the fastest anything can happen in a metallic crystal is nine orders of magnitude slower than the typical time in which the nucleus created by fusing deuterium plays out its drama of fusion and breakup. In other words, when the nucleus is doing its thing, the atoms of the crystal are far away and frozen in time. Finally, the energy released in the nuclear reaction is so large that the crystal has no means to absorb it, unless it is spread out instantaneously, over vast distances, by some mechanism not now known (presumably, the same mechanism would have to account for why no gamma ray is emitted). In short, according to everything we know about the behavior of matter and nuclei, cold fusion is impossible. This is what I meant when I said that cold fusion is an experiment whose result is contrary to prevailing theory.

In spite of all that, scientists are aware that they must be prepared, from time to time, to be surprised by a phenomenon they previously thought to be impossible. There are two recent examples that seem relevant to the cold fusion problem. One is high temperature superconductivity, and the other is the Mössbauer effect.

In 1986, two Swiss physicists, J. Georg Bednorz and A. Karl Mueller, announced the discovery of a material that remained superconducting at temperatures as high as 30 kelvins. Superconductivity is itself a phenomenon that violates the trained intuition of physicists: at sufficiently low temperature, many metals can conduct electricity without any resistance at all, while simultaneously expelling completely any applied magnetic field. This behavior is so bizarre that it took nearly half a century after its discovery, in 1911, before an acceptable theoretical explanation was formulated. However, if nature was going to play such weird tricks on us, at least these tricks were confined to the privacy of the physics laboratory by the requirement of extreme low temperature. Before Bednorz and Mueller, it was well known that superconductivity could never exist at a temperature higher than 35 kelvins. After Bednorz and Mueller, it was only a matter of months before materials were discovered that remained superconducting up to 100 kelvins. That's still pretty cold-normal room temperature is about 300 kelvins-but the shocking impact of that discovery on the scientific community is hard to overestimate. The discovery of high temperature superconductivity in 1986 set the stage for the announcement--and at least temporary acceptance of the possibilityof cold fusion in 1989.

The Mössbauer effect, discovered 30 years earlier, was another completely unexpected phenomenon that seemed to have an even more direct bearing on cold fusion. As we've already seen, cold fusion is hard to swallow in part because it is so implausible to believe that a nuclear reaction might be altered in any meaningful way by taking place in a crystal. Yet the Mössbauer effect was an example in which precisely that does seem to occur.

When a nucleus has too much energy, it must find some means to get rid of the excess. For example, we've already seen that when two deuteriums fuse, the resulting nucleus, which has far too much energy, can actually break up in any of three ways. In all three cases, however, the result is two fragments that fly off in opposite directions. Mössbauer's discovery was that, in certain cases when a nucleus in a crystal gives up its excess energy by emitting a gamma-ray photon, instead of the photon going one way and the nucleus the other way as would normally be expected, there is a substantial probability that the photon will fly off and the nucleus will stand still. Instead of the nucleus recoiling (just as a rifle does when it fires a bullet) the recoil is taken up by the entire crystal, resulting in essentially no motion at all. The net result is that the gamma-ray photon emitted by a nucleus in a crystal can have slightly more energy than the gamma-ray photon the same nucleus would have emitted in a vacuum. Our carefully trained intuition-which says that nuclei are unaffected by being in a crystal because they exist in entirely separate realms of distance, time, and energy- 
has been violated. If our intuition can be violated by the Mössbauer effect, then why not by cold fusion?

That's a good question, and there are very good answers. First, the Mössbauer effect can be observed only for a few special nuclear reactions in which the energy that must be disposed of is much smaller, and the time the nucleus takes to get rid of it much larger, than in the cold fusion reaction. In other words, it occurs precisely in those special cases where our argument that the nucleus and the crystal act on incompatible scales of time and energy no longer holds true. Second, even then, the Mössbauer effect does not change the intimate details of the nuclear reaction, such as the emission (or not) of a gamma-ray photon, or the probabilities of the various possible ways of giving up its excess energy. It is precisely these details that must be changed if cold fusion is real. Finally, the Mössbauer effect is in a sense the exact opposite of what is supposed to happen in cold fusion: instead of the nuclear recoil energy somehow turning into heat in the atomic lattice, the Mössbauer effect is interesting precisely because it's the special case in which no heat at all is produced.

Nevertheless, in spite of all the differences, many scientists instantly thought of the Mössbauer effect when they first heard of cold fusion. The discovery of the Mössbauer effect had been unexpected, but, once it happened, it was quickly and satisfactorily explained within the framework of conventional theory. It proved that there are still genuine surprises waiting for us that, once understood, don't violate conventional physical laws. And it also proved that there is at least some realm in which nuclear physics and solid state physics affect one another. Those are just the things you have to be willing to believe in order to be prepared to accept cold fusion, at least provisionally.

In any case, immediately after the press conference in Utah, most scientists were willing at least to suspend judgment for a while, to give cold fusion a chance. It was precisely during this crucial probationary period (so to speak) that cold fusion science went berserk. Many scientists tried their own hand at it. Those who succeeded, or seemed to succeed, held press conferences. Those who failed generally quietly let the matter drop and went on to other things. It would be difficult to devise a worse way of doing science. Among the exceptions to that behavior were Lewis, Barnes, and Koonin, of Caltech. They pursued every lead with relentless tenacity and Popperian rigor, repeating every experiment, calculating every effect, looking not merely for

\section{Cold fusion bad \\ been given its \\ chance, a suspen- \\ sion of disbelief \\ no matter how \\ unlikely it \\ seemed, and it \\ bad failed to \\ prove itself.}

positive or negative results, but also for explanations of the false positive results that others were reporting - in other words, finding the mistakes of other scientists. These they found in abundance. Far from publicizing their work, they were so secretive that rumors started to circulate, and even appeared in the press, that they were protecting positive results. [For an in-depth account of Caltech's "Quest for Fusion," see EES Summer 1989.] Finally, they were able, five weeks after the Utah press conference, to stand before their colleagues in Baltimore and, piece by piece, in vivid detail, demolish the case for cold fusion. Cold fusion had been given its chance, a suspension of disbelief no matter how unlikely it seemed, and it had failed to prove itself. Cold fusion was dead in the eyes of respectable science.

Meanwhile, back in Frascati, Franco Scaramuz$z i$ and his group of young researchers were not quite prepared to give up. Just as the drama in Italy was little noticed in America, events in Baltimore seem far away when you are in Rome. Franco himself had had, not just 15 minutes of fame, but a month of it, and it showed no signs of letting up. He was a hero, not only to the general public, but also to all his colleagues in the agency ENEA, and ENEA itself had suddenly shed its reputation for bumbling bureaucratic ineptitude. This was not a propitious moment to throw in his hand just because Lewis, Barnes, and Koonin didn't approve.

Besides, he had his own data, and he believed in them. Nothing convinces a scientist nearly as effectively as the experience of seeing data emerge from one's own experiment. In this case there 

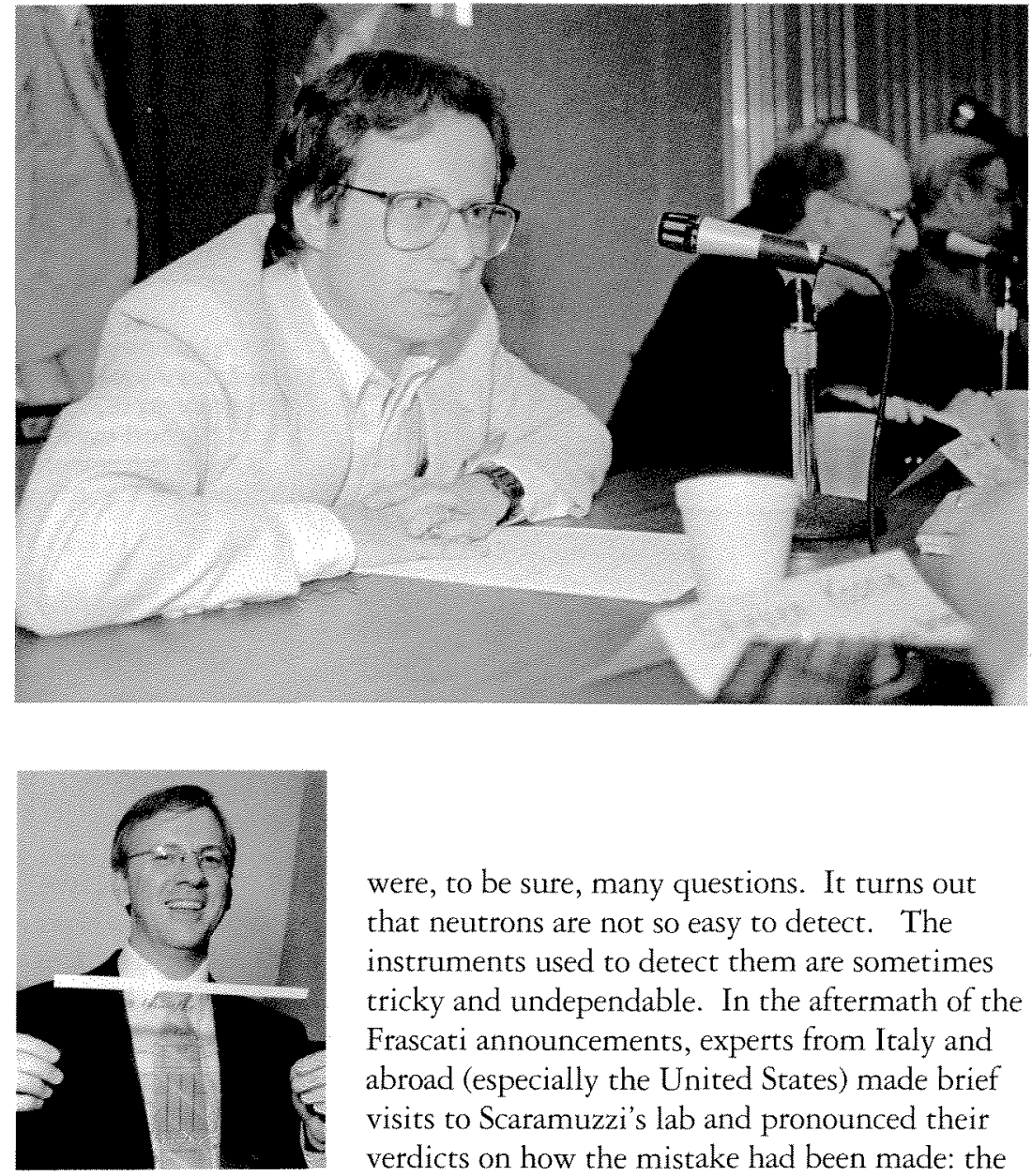

Below left: Physicist Steven Jones from Brigham Young University, here presenting his data at Columbia University on March 31, 1989, claimed to detect not heat but neutrons, as did Scaramuzzi. were, to be sure, many questions. It turns out that neutrons are not so easy to detect. The instruments used to detect them are sometimes tricky and undependable. In the aftermath of the Frascati announcements, experts from Italy and abroad (especially the United States) made brief visits to Scaramuzzi's lab and pronounced their verdicts on how the mistake had been made: the apparent bursts of neutrons were really artifacts due to changes in temperature, or humidity, or power surges on the (notoriously unstable) Frascati lab electric system, or other electronic problems. I remember during my visit that summer talking to one of Franco's young colleagues, Antonella De Ninno. "Do they think we're stupid?" she asked me angrily. "Of course we thought of all those possibilities and eliminated them!" Once the group was convinced they had seen the real thing, they weren't about to give up because someone had made a speech in Baltimore.

There was also a bit of wriggle-room available. At the Baltimore meeting, Pons and Fleischmann did not attend, but Jones did. He was the first speaker. He pointed out just how small was the effect he claimed to see compared to what Pons and Fleischmann were claiming (as we have seen, the number of neutrons that come out appears to be smaller than expected by about 10 orders of magnitude). Thus it seemed possible that even if cold fusion didn't produce heat (the PonsFleischmann claim) maybe something was going on at a much lower level, producing a few neutrons (as Jones and Scaramuzzi, among others, claimed). Of course, Barnes at Caltech had shown there were no neutrons just as effectively

\section{Left: Steve Koonin, Caltech professor of theoretical physics, delivers the coup de grace to cold fusion at a Baltimore meeting of the American Physical Association on May 1-a mere five weeks after discovery of the phenomenon was first announced.}

as Lewis had shown there was no heat (and Koonin had shown there was no theory), and furthermore, if cold fusion merely produced a few neutrons instead of a lot of heat it certainly wasn't going to solve the world's energy problems. Nevertheless, it seemed at the time that there just might be two kinds of cold fusion, the bad kind (heat) that Koonin and Lewis had put to rest, and the good kind (neutrons) that was still scientifically respectable. The Italian press made much of the fact that "Italian Cold Fusion" was of the good kind, not noticing that the good kind of cold fusion, if it existed, would be a scientific curiosity, not an epochal discovery.

In any case, after the furor died down, cold fusion research continued in a number of places. The key to continued research is financial; to paraphrase California politician Jesse Unruh, money is the mother's milk of scientific research. In the United States, the government funding agencies quickly fell into line with scientific orthodoxy and ceased funding anything that smacked of cold fusion. However, the industrysupported Electric Power Research Institute decided to put up some funds, just in case. In Japan, Toyota and MITI, apparently willing to accept some short-term risk in exchange for the possibility of a big payoff later, agreed to put up a few yen. In Italy, ENEA, with its budget and prestige resting on cold fusion, could hardly refuse to permit Scaramuzzi and his group to press on. In other places, where scientists were given modest financial support and some discretion in how to spend it, some chose to pursue cold fusion. In spite of the disapproval of the 


\section{In the continuing Italian experiments, Fabrizio Marini (left) and Dr. Antonio Frattolillo check the vacuum system for the high-resolution mass spectrometer (hanging off the top), used to detect helium 4 , the end product of cold fusion.}

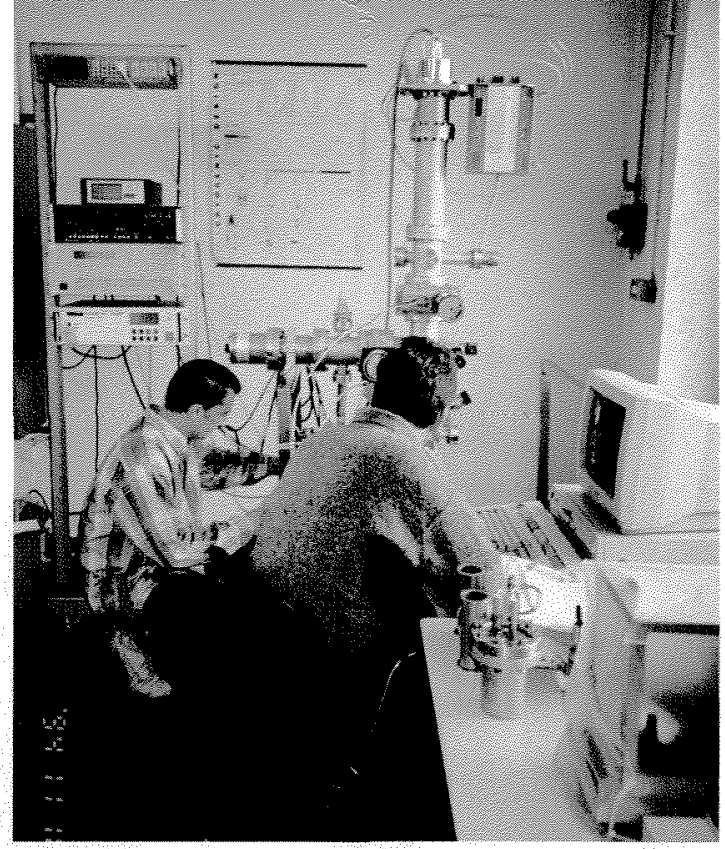

worldwide scientific establishment, some cold fusion research kept right on going.

Scaramuzzi and his colleagues did not devote all of their attention to cold fusion. At the same time all this was going on, they also developed the world's best device for firing frozen pellets of solid deuterium into the plasma used to create hot fusion. If hot fusion were ever to produce useful energy, this is the means by which the reactor's deuterium fuel would be replenished. They were also responsible for the sophisticated cooling device that rendered it possible to make observations of infrared cosmic radiation in outer

There was no dependable recipe for coaxing bursts of neutrons out of the cold fusion cell. As long as that was true the world of respectable science was not going to pay any attention even to the "good kind" of cold fusion. space, using relatively inexpensive long-range balloon flights instead of satellites to rise above most of the earth's atmosphere. In both of these tasks, they were doing successful high technology in the very center of the scientific mainstream.

But they also continued to pursue cold fusion. Reacting to criticism of the primitive technique they had used to detect neutrons, they purchased the best neutron-detection system in the world, essentially identical to the one used by Charlie Barnes at Caltech. Going one better, they installed it in physics laboratories that had been excavated under a mountain called the Gran Sasso, a two-hour drive from Rome. Anywhere on the surface of the earth, there are always some neutrons buzzing around due to cosmic radiation from outer space. This so-called "background" has to be subtracted from the neutrons produced by any other phenomenon such as cold fusion. In the galleries under the Gran Sasso, the shielding effect of the mountain reduces the cosmic-ray neutron background nearly to zero. That's why the laboratory was built there. An automated system was set up to monitor the neutron counter while running the temperature of a Scaramuzzitype deutetium gas cell up and down. Every week or so, a member of the group would have to drive out to the Gran Sasso lab, check out the counters, replenish the supply of liquid nitrogen, and bring back the data. No one could accuse them any longer of being unsophisticated about neutron work. This experiment, however, like their own earlier work and many other experiments blossoming around the world, produced positive results, but only sporadically. There was no dependable recipe for coaxing bursts of neutrons out of the cold fusion cell. As long as that was true the world of respectable science was not going to pay any attention even to the "good kind" of cold fusion.

Then they decided to pursue the "bad kind" as well. They built a well-designed electrolysis cell, capable of detecting excess heat if any were produced, while obviating some of the shortcomings for which previous excess-heat experiments had been criticized. In 1992 and 1993, these experiments, too, gave positive results. The cell would produce very substantial amounts of heat (a few watts) for periods of tens of hours at a time. As in the neutron experiments, these episodes were sporadic, occurring seemingly at random, but at least they occurred only when the fluid in the cell was heavy water (containing deuterium), never when it was light water (containing ordinary hydrogen). The lack of this kind of control experiment had been one of the points of criticism of Pons and Fleischmann. By this time, however, the world of mainstream science was no longer listening.

I went to visit Franco in December 1993 , when he returned from the Maui conference. While I was there, he summarized the results of the conference in a seminar presented to the Physics Faculty at the University of Rome " $L a$ Sapienza," the first university of Rome; now there are two more). This was in itself an unusual event. The Physics Faculty of the University of Rome today is comparable to the physics department at a good American state university. For them, inviting Franco to speak about cold fusion was a daring excursion to the fringes of science. Feeling that this was a rare opportunity, Franco prepared his talk with meticulous care.

At the seminar, Franco's demeanor was subdued, and his presentation was, as always, reserved and correct. Nevertheless, his message was an optimistic one for cold fusion. In essence (although Franco didn't say it in these words), each of the criticisms that Nate Lewis had cor- 
Waiting for fusion. (From left) Fabrizio Marini, Giuseppe Lollobattista, Dr.

Aurelio La Barbera, Domenico Lecci, and Dr. Luciano Bertalot, look for heat (the "bad kind" of cold fusion) from measurements in progress in the calorimeters (inside the white boxes behind them).

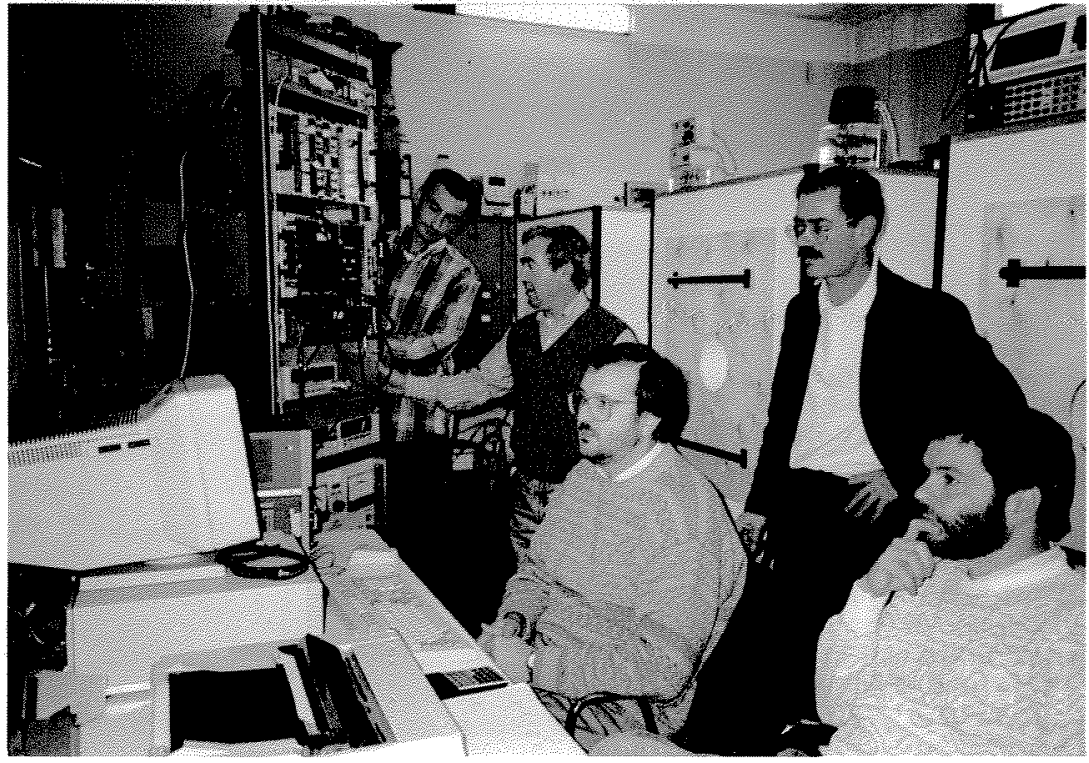

Even more impor-

tant, there was

reason to believe

that the magic

missing factor, the

secret ingredient of

the recipe that

accounted for why

cold fusion

experiments only

sporadically gave

positive results,

might finally

bave been

discovered. rectly leveled at the experiments of Pons and Fleischmann had been successfully countered by new experiments reported at the conference. Even more important, there was reason to believe that the magic missing factor, the secret ingredient of the recipe that accounted for why cold fusion experiments only sporadically gave positive results, might finally have been discovered.

One of the criticisms that Nate had used with telling effect is that local hot-spots often develop in electrolysis experiments (Nate is himself an electrochemist, and a consummate experimentalist). By placing their thermometer at an accidental hot spot, and by neglecting the elementary precaution of stirring the bath in their cells, Pons and Fleischmann could easily have fooled themselves into thinking there was excess heat where none really existed. To counter this argument, Franco could point to the design of the cell used by his own Frascati group, which carefully averaged the temperature of the entire cell, rather than measuring it at a single point (many other groups had introduced mechanical stirrers into their cells). Another objection that had been raised was that, if heat was generated in these experiments, it was the result of some uninteresting chemical process rather than of nuclear fusion. Chemical processes that generate heat are not uncommon in electrolysis experiments. The strongest argument for nuclear fusion (given the near absence of the neutrons and tritium) was that the amount of heat generated was far too large to be due to any chemical process. That would be true, the critics replied, if the chemicals were being generated at the same time as the heat. However; all of these cold fusion cells had long, dormant periods during which energy was being pumped in and no excess heat was being produced. The heat finally liberated in the "cold fusion" episodes might just have been chemical energy stored up during the dormant periods. In other words, the cells were not producing more energy than was being put into them; they were just storing up energy and releasing it in bursts. Not only would that be much less exciting than a discovery of controlled nuclear fusion, it also wouldn't be of much help in our struggle against the oil barons. Now this argument could be countered as well: there were what appeared to be very careful experiments in which the total amount of energy consumed during the dormant periods was minuscule compared to the amount of heat liberated during the active periods.

Finally, one of the most damaging criticisms of Pons and Fleischmann was that they had failed to do control experiments. Nuclear fusion (if it occurred) should only have been possible (if it were possible) when electrolysis was done in heavy water, made of deuterium. It should not be possible using ordinary water, made of ordinary hydrogen. Now many groups, including Franco's, had done the necessary control experiments, and obtained the necessary confirming results (no heat in the controls). Unfortunately, other groups reported that they did observe excess heat in experiments done with ordinary light water. Franco dutifully reported these results at the Rome seminar, expressing only muted disapproval ("In my opinion, these results have not been consolidated," he said). 
If cold fusion ever gains back the scientific respectability that was squandered in March and April of 1989 , it will be the result of $a$ long, difficult battle that has barely begun.
All of this was much less important than the fact that cold fusion experiments, if they gave positive results at all, gave them only sporadically and unpredictably. When Bednorz and Mueller announced the discovery of high temperature superconductivity in 1986, no one carped about control experiments, because, once the recipe was known, any competent scientist could make a sample and test it and it would work immediately. If, at their press conference, Pons and Fleischmann had given a dependable recipe for producing excess heat, they very likely would be Nobel Prize winners now (as Bednorz and Mueller are) rather than social outcasts from the community of scientists. The essential key to the return of cold fusion to scientific respectability is to find the missing ingredient that would make the recipe work every time.

Experiments done in the United States and Japan, and reported at the Maui meeting, indicate that the missing ingredient may have been found. In all the various cold fusion experiments, the first step is to load deuterium into the body of metallic palladium. The issue is how much deuterium gets into the metal. The ratio of the number of atoms of deuterium in the metal to the number of atoms of palladium is called $x$. It turns out, by means of electrolysis, or by putting the metal in deuterium gas, that it is rather easy to get $x$ up to the range of about 0.6 or 0.7 . That is already a startlingly high figure. If there are almost as many deuterium atoms as palladium atoms in the material, the density of deuterium (a form of hydrogen) is essentially equal to that of liquid hydrogen rocket fuel, which can ordinarily exist only at extreme low temperatures. In other words, palladium (and certain other metals including titanium) soak up almost unbelievable. amounts of hydrogen or deuterium if given the chance. This is far from a new discovery. However, according to the experiments reported at Maui, $x=0.6$ or 0.7 is not enough to produce cold fusion. Both American and Japanese groups showed data indicating there is a sharp threshold at $x=0.85$. Below that value (which can only be reached with great difficulty and under favorable circumstances) excess heat is never observed. But, once $x$ gets above that value, excess heat is essentially always observed, according to the reports presented at Maui and recounted by Franco Scaramuzzi in his seminar at the University of Rome.

The audience at Rome, certainly the senior professors who were present, listened politely, but they did not hear what Franco was saying (that much became clear from the questions that were asked at the end of the seminar, and comments that were made afterward). If they went away with any lasting impression at all, it was just the sad realization that a fine scientist like Franco had not yet given up his obsession with cold fusion. They cannot be blamed. Any other audience of mainstream scientists would have reacted exactly the same way. If cold fusion ever gains back the scientific respectability that was squandered in March and April of 1989, it will be the result of a long, difficult battle that has barely begun.

Recently, I told this story in a philosophy course we teach at Caltech called "Ethics of Research." The first question, when I finished my tale, was, do I believe in cold fusion? The answer is no. Certainly, I believe quite firmly the theoretical arguments that say cold fusion is impossible. On the other hand, however, I believe equally firmly in the integrity and competence of Franco Scaramuzzi and his group of coworkers at Frascati. I was disturbed when I saw that Franco had gotten caught in the web of science-by-news-conference in April 1989 (although I was truly pleased that he finally got the long overdue recognition his agency ENEA owed him), and I was even more distressed when I learned that Franco and his group had observed excess heat (the "bad kind" of cold fusion). I have looked at their cells, however, and looked at their data, and it's all pretty impressive. The Japanese experiment showing that heat nearly always results when $x$ is greater than 0.85 looks even more impressive on paper. It seems a particularly elegant, well-designed experiment, at least to the untutored eye of a physicist. (What do I know about electrochemistry?) What all these experiments really need is critical examination by accomplished rivals intent on proving them wrong. That is part of the normal functioning of science. Unfortunately, in this area, science is not functioning normally. There is nobody out there listening.

I suppose that, if nuclear fusion really does take place whenever $x$ is greater than 0.85 in palladium, the world of conventional science will eventually be forced to take notice. If not, then the whole story I have told you is nothing but a curious footnote to a bizarre and ugly episode in the history of science. Either way, I think the story illuminates the inner dynamics of the scientific enterprise in a way that few other stories have done. For that reason alone, it may be worth telling.

Although not an inside player in the cold fusion game, David Goodstein, vice provost and professor of physics and applied physics, is nevertbeless a tireless and articulate observer of the scientific scent, an occupation from which $\mathrm{E} \& \mathrm{~S}$ bas often benefited. 